\title{
Influence of Pruning Levels and Fertilizer Rates on Growth and Yield of Jatropha curcas L. (Physic Nut)
}

\author{
R.G. Sumed ${ }^{1 *}$, Shahbaz Noori ${ }^{2}$, G.O. Manjunath ${ }^{1}$, H. Shivanna ${ }^{3}$ and S.K. Patil ${ }^{1}$ \\ ${ }^{1}$ Department of Forest Products and Utilization, ${ }^{2}$ Department of Silviculture and \\ Agroforestry, ${ }^{3}$ Department of Forest Biology and Tree Improvement, College of Forestry, \\ Sirsi (UAS, Dharwad), India \\ *Corresponding author
}

\section{A B S T R A C T}

\section{Keywords}

Biofuel, Fruit yield, Physic nut

(Jatropha curcas

L.), Pruning, Seed yield

Article Info

Accepted:

10 October 2019

Available Online:

10 November 2019
Appropriate canopy management and proper application of fertilizer under different growing conditions and agronomic practices can obtain reliable yield of Jatropha curcas L. (Physic Nut). The objective of study was to determine the influence of pruning level in first year and fertilizer rate of combined NPK in the first and second year on growth and yield of Physic nut, conducted at Agricultural Research Station, Prabhunagar (Dharwad). The seeds were dibbled at $3 \times 2 \mathrm{~m}$ spacing apart. A split plot design with three replications was used. Four pruning levels of $100 \mathrm{~cm}, 150 \mathrm{~cm}, 200 \mathrm{~cm}$ and No pruning from the ground were assigned in main plots and combination of NPK fertilizers levels (40:40:40, 60:60:60, 80:80:80 N: $\mathrm{P}_{2} \mathrm{O}_{5}: \mathrm{k}_{2} \mathrm{O}$ g/ plant) were arranged randomly in subplots. All pruning levels from the ground did not have significant effects on number of branches and collar diameter, whereas application of fertilizer did increase number of branches, collar diameter, fruit yield and seed yield $(15.77,18.71 \mathrm{~cm}, 316.65$ and $727.96 \mathrm{~g}$ per plant respectively). Number of branches and collar diameter of Jatropha were significantly higher in pruning at $100 \mathrm{~cm}$ height from ground level (16.94 and $17.04 \mathrm{~cm}$ respectively) as compared to other pruning levels. It is thus recommended to prune Physic nut at $200 \mathrm{~cm}$ from the ground and apply fertilizer at the rate of (80:80:80 $\mathrm{g} \mathrm{H}: \mathrm{P}_{2} \mathrm{O}_{5}: \mathrm{K}_{2} \mathrm{O}$ per plant) as it recorded maximum seed yield per plant (1142.95 g) and per hectare (1903.68 kg.) respectively over other treatment combinations.

\section{Introduction}

Jatropha curcas L. (Physic Nut) is an underutilized small tree native to the Central and South America. The plant has been distributed to other parts of the world including Southeast Asia, India and Africa (Tan et al., 2002). The crop flowers once a year during the rainy season (Raju and Ezradanam, 2002). However, it can flower all year around under 
irrigated conditions and its yield is much higher (Heller, 1996). Physic nut is a promising crop for biofuel production (Sujatha et al., 2008). It is well adapted to semi-arid conditions although, it yields better under more humid conditions (Achten et al., 2008). It can be grown in the average temperatures between 20 and $28^{\circ} \mathrm{C}$, a range of rainfall between 250 and $3000 \mathrm{~mm}$ and a wide range of soils although well drained and aerated soil is most favourable.

Physic nut is well adapted to marginal soils with low nutrient content (Heller, 1996) and annual seed yield of 2-3 $\mathrm{t} \mathrm{ha}^{-1}$ has been reported in semi-arid areas (Kumar and Sharma, 2008). However, the crop still requires high demand for $\mathrm{N}$ and $\mathrm{P}$ fertilization for high biomass production and high yield (Foidl et al., 1996) and its annual seed yield of $5 \mathrm{t}$ ha has been reported under good management and favourable environment (Kumar and Sharma, 2008). As an underutilized crop with high potential for biodiesel production, yield of physic nut is still low compared to other crops such as sugarcane (Saccharum officinarum), cassava (Manihot esculenta) and oil palm (Elaeis guineensis). Drought, low soil fertility and lack of external sources of nutrients are major constraints. Production of Physic nut is also constrained by non availability of quality planting material and agro-techniques.

Systematic nutrient studies are scarce for physic nut and few studies are available in the literature. Yin et al., (2010) observed that different levels of nitrogen fertilizer significantly affected growth, development, kernet set and yield of physic nut. Novoa and Loomis (1981) also found that application of nitrogen fertilizer significantly increased leaf area index, leaf area duration, crop photosynthetic rate and radiation interception and radiation use efficiency. Further investigations are still required to establish fertilizer recommendation for physic nut of different ages and in different growing conditions.

Physic nut grown under commercial plantations need to be pruned to control plant size and to provide acceptable yield. Pruning is believed to assist the production of more branches and to stimulate abundant and healthy inflorescences, thus finally enhancing good fruit setting and seed yield (Gour, 2006). Acheten et al., (2008) suggested that pruning should be done in dormant period. The ten year old tree should be cut back to a stump of $45 \mathrm{~cm}$ and the tree will begin yielding again within 1 year. They also suggested annual pruning of the plantations by cutting $2 / 3$ of terminal branches. Little information on the effects of pruning methods and fertilizer rates on yield of physic nut of different ages under rainfed conditions in the tropics and further investigation are required to optimize pruning methods and rates of applied fertilizer. The objective of the study was to determine the influence of pruning level in the first year and fertilizer rater of combined with NPK on growth and yield of physic nut.

\section{Materials and Methods}

The experiment was conducted at Agricultural Research Station of Prabhunagar, situated under University of Agricultural Sciences, Dharwad during September 2016. The soil type is black with coarse texture. Average annual rainfall recorded was about $1069 \mathrm{~mm}$ with average mean air temperature ranging from $30{ }^{\circ} \mathrm{C}$. The plantation was established in the year 2016 and the experiment was initiated in the year of 2016 by dibbling seeds $3 \times 2 \mathrm{~m}$ spacing to evaluate the influence of pruning methods and rate of fertilizer application on growth and yield of physic nut. The experiment was set up in split plot design with three replication. The main plot consisted of four pruning levels of $100 \mathrm{~cm}, 150 \mathrm{~cm}, 200$ 
$\mathrm{cm}$ and no pruning from the ground and sub plots comprised combination of NPK fertilizers levels (40:40:40, 60:60:60, 80:80:80 $\mathrm{N}: \mathrm{P}_{2} \mathrm{O}_{5}: \mathrm{K}_{2} \mathrm{O}$ g/ plant). Each plot had three rows with $3 \mathrm{~m}$ long and spacing of $2 \mathrm{~m}$ and 1 $\mathrm{m}$ in between the plants within a row and could accommodate nine plants. Pruning was carried out in 2016 and fertilizer was applied as a single dose to the crop soon after pruning. The crop was allowed to grow until harvest under rainfed conditions. Weeding was done as needed. Conventional tillage was also practiced between the rows of plants. The crop was allowed to grow in 2017 without pruning, but the fertilizer at the proposed rate ratio was applied to the crop. Other management practices were similar to those in 2016.

\section{Results and Discussion}

Combined analysis of variance showed significant difference between among pruning levels and fertilizer rate for number of branches, collar diameter, fruit yield and seed yield per plant. The number of branches recorded at 450 days after treatment ranged from 13.21 $\left(\mathrm{F}_{1}\right)$ to $15.77\left(\mathrm{~F}_{3}\right)$ among a fertilizers levels and $9.64\left(\mathrm{P}_{4}\right)$ to $16.94\left(\mathrm{P}_{1}\right)$ among the pruning levels. It seemed likely that taller pruning gave more branches than shorter pruning. Application of fertilizers levels differed statistically while the pruning levels at $150 \mathrm{~cm}$ and $200 \mathrm{~cm}$ were on par with each other. No pruning resulted in large number of primary branches (16.94) in comparison to pruning levels. The interaction effect revealed that the treatment combination $100 \mathrm{~cm}$ pruning level with fertilizer dose of 80:80:80 $\mathrm{N}: \mathrm{P}_{2} \mathrm{O}_{5}: \mathrm{K}_{2} \mathrm{O}$ g/ plant reported 22.10 numbers of branches showing significantly superior over all other treatment combinations while the least number of branches (9.17) was recorded under treatment of no pruning level combined with 60:60:60 N: $\mathrm{P}_{2} \mathrm{O}_{5}: \mathrm{K}_{2} \mathrm{O}$ g/ plant. Supply of sufficient amount of nitrogen (80 g.) made it to produce more number of branches due to enhanced photosynthetic rate of the plant. Thus fertilizer level of 80:80:80 $\mathrm{N}: \mathrm{P}_{2} \mathrm{O}_{5}: \mathrm{K}_{2} \mathrm{O}$ g/ plant yielded more numbers of branches (3.51) at 180 days after imposition of treatment (Table 1). The collar diameter on 450 days of experiment ranged from $13.96 \mathrm{~cm}$ to $18.71 \mathrm{~cm}$ among fertilizers levels and 14.56 $\mathrm{cm}$ to $17.04 \mathrm{~cm}$ among the pruning levels. No Pruning treatment recorded better collar diameter $(17.04 \mathrm{~cm})$ significantly superior other levels while pruning at $150 \mathrm{~cm}$ and 200 $\mathrm{cm}$ on par with each other. The combined treatment of combination of 80:80:80 N: $\mathrm{P}_{2} \mathrm{O}_{5}$ : $\mathrm{K}_{2} \mathrm{O}$ g/ plant with $150 \mathrm{~cm}$ pruning level from ground recorded superior collar diameter growth (21.07) over all other treatment combination (Table 2).

Number of Fruit per plant ranged from 210.42 to 316.65 among fertilizers levels and 184.51 to 386.35 among pruning levels. Higher fruit number (495.80) was recorded in treatment combination of 80:80:80 N: $\mathrm{P}_{2} \mathrm{O}_{5}: \mathrm{K}_{2} \mathrm{O}$ g/ plant with $200 \mathrm{~cm}$ pruning level from ground while lowest fruit yield (140.20) was observed in no pruned treatment combination with recorded 40:40:40 N: $\mathrm{P}_{2} \mathrm{O}_{5}: \mathrm{K}_{2} \mathrm{O}$ g/ plant. The higher doses of nitrogen application in Jatropha yield more number of fruits. Phosphorous application at $80 \mathrm{~g}$. per plant had improved the fertilization of flower and later retention of fruits which were formed thus leading to more number of fruits. Increased fruits under K-fertilization can be attributed to assimilates and translocation of nutrients. The seed yield per plant ranged from 464.10 gram to 727.96 gram among fertilizers levels and 417.59 gram to 877.05 gram among pruning levels. The maximum seed yield (1142.95 gram) was recorded in the treatment combination of $200 \mathrm{~cm}$ pruning level from ground with 80:80:80 N: $\mathrm{P}_{2} \mathrm{O}_{5}: \mathrm{K}_{2} \mathrm{O}$ g/ plant while lowest seed yield (310.29 g) was observed in treatment combination of no pruning with 40:40:40 N: $\mathrm{P}_{2} \mathrm{O}_{5}: \mathrm{K}_{2} \mathrm{O}$ g/ plant (Table 3). 
Table.1 Influence of pruning and fertilizer levels on number of branches in Jatropha (Jatropha curcas)

\begin{tabular}{|c|c|c|c|c|c|c|c|c|c|c|c|c|c|c|c|c|}
\hline \multirow{2}{*}{$\begin{array}{c}\text { Treatment } \\
\text { Combinations }\end{array}$} & \multicolumn{4}{|c|}{ June } & \multicolumn{4}{|c|}{ September } & \multicolumn{4}{|c|}{ December } & \multicolumn{4}{|c|}{ March } \\
\hline & $\mathbf{F}_{1}$ & $\mathbf{F}_{2}$ & $\mathbf{F}_{3}$ & Mean & $\mathbf{F}_{1}$ & $\mathbf{F}_{2}$ & $\mathbf{F}_{3}$ & Mean & $\mathbf{F}_{1}$ & $\mathbf{F}_{2}$ & $\mathbf{F}_{3}$ & Mean & $\mathbf{F}_{1}$ & $\mathbf{F}_{2}$ & $\mathbf{F}_{3}$ & Mean \\
\hline$P_{1}-100 \mathrm{~cm}$ & 1.91 & 2.41 & 5.25 & 3.19 & 7.66 & 8.30 & 11.41 & 9.12 & 11.33 & 11.42 & 19.00 & 13.91 & 14.16 & 14.58 & 22.10 & 16.94 \\
\hline$P_{2}-150 \mathrm{~cm}$ & 2.58 & 3.01 & 2.91 & 2.83 & 7.58 & 8.00 & 8.83 & 8.13 & 11.67 & 12.75 & 12.58 & 12.33 & 14.75 & 15.17 & 15.50 & 15.14 \\
\hline$P_{3}-200 \mathrm{~cm}$ & 3.00 & 3.03 & 3.47 & 3.16 & 8.41 & 9.08 & 8.41 & 8.63 & 12.00 & 13.33 & 12.08 & 12.47 & 14.50 & 15.67 & 15.17 & 15.11 \\
\hline $\begin{array}{l}\mathbf{P}_{4}-\mathrm{No} \\
\text { pruning }\end{array}$ & 1.50 & 2.00 & 2.41 & 1.97 & 4.33 & 4.67 & 5.58 & 4.86 & 7.58 & 6.84 & 8.25 & 7.55 & 9.41 & 9.17 & 10.34 & 9.64 \\
\hline Mean & 2.25 & 2.61 & 3.51 & 2.78 & 7.00 & 7.51 & 8.86 & 7.79 & 10.64 & 11.83 & 12.98 & 11.81 & 13.21 & 13.64 & 15.77 & 14.20 \\
\hline $\begin{array}{c}\text { For } \\
\text { comparing }\end{array}$ & \multicolumn{2}{|c|}{ S. Em ( $( \pm)$} & \multicolumn{2}{|c|}{ CD 5\% } & \multicolumn{2}{|c|}{ S. Em ( $( \pm)$} & \multicolumn{2}{|c|}{ CD 5\% } & \multicolumn{2}{|c|}{ S. $\operatorname{Em}( \pm)$} & \multicolumn{2}{|c|}{ CD 5\% } & \multicolumn{2}{|c|}{ S. $\operatorname{Em}( \pm)$} & \multicolumn{2}{|c|}{ CD 5\% } \\
\hline Pruning (P) & \multicolumn{2}{|c|}{0.19} & \multicolumn{2}{|c|}{0.57} & \multicolumn{2}{|c|}{0.25} & \multicolumn{2}{|c|}{0.75} & \multicolumn{2}{|c|}{0.31} & \multicolumn{2}{|c|}{0.91} & \multicolumn{2}{|c|}{0.24} & \multicolumn{2}{|c|}{0.71} \\
\hline $\begin{array}{l}\text { Interaction } \\
\text { (FxP) }\end{array}$ & \multicolumn{2}{|c|}{0.34} & \multicolumn{2}{|c|}{1.01} & \multicolumn{2}{|c|}{0.44} & \multicolumn{2}{|c|}{1.29} & \multicolumn{2}{|c|}{0.54} & \multicolumn{2}{|c|}{1.58} & 0. & 42 & & 22 \\
\hline
\end{tabular}

$F_{1^{-}}$40:40:40; $\mathrm{F}_{2^{-}}$60:60:60; $\mathrm{F}_{3^{-}}$80:80:80 N; $\mathrm{P}_{2} \mathrm{O}_{5}: \mathrm{K}_{2} \mathrm{O}_{5} \mathrm{~g} / \mathrm{plant}$ 
Int.J.Curr.Microbiol.App.Sci (2019) 8(11): 1071-1077

Table.2 Influence of pruning and fertilizer levels on collar diameter in Jatropha curcas

\begin{tabular}{|c|c|c|c|c|c|c|c|c|c|c|c|c|c|c|c|c|}
\hline \multirow{2}{*}{$\begin{array}{c}\text { Treatment } \\
\text { Combinations }\end{array}$} & \multicolumn{4}{|c|}{ June } & \multicolumn{4}{|c|}{ September } & \multicolumn{4}{|c|}{ December } & \multicolumn{4}{|c|}{ March } \\
\hline & $\mathbf{F}_{1}$ & $\mathbf{F}_{2}$ & $\mathbf{F}_{3}$ & Mean & $\mathbf{F}_{1}$ & $\mathbf{F}_{2}$ & $\mathbf{F}_{3}$ & Mean & $\mathbf{F}_{1}$ & $\mathbf{F}_{2}$ & $\mathbf{F}_{3}$ & Mean & $\mathbf{F}_{1}$ & $\mathbf{F}_{2}$ & $\mathbf{F}_{3}$ & Mean \\
\hline 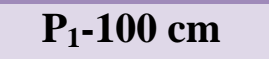 & 7.86 & 7.94 & 10.20 & 8.67 & 9.78 & 10.00 & 12.16 & 10.64 & 12.20 & 12.01 & 15.61 & 13.27 & 14.26 & 14.61 & 20.60 & 16.50 \\
\hline$P_{2}-150 \mathrm{~cm}$ & 7.01 & 7.83 & 12.38 & 9.07 & 8.11 & 10.20 & 16.10 & 11.47 & 11.13 & 13.30 & 18.75 & 14.40 & 14.01 & 16.03 & 21.05 & 17.09 \\
\hline$P_{3}-200 \mathrm{~cm}$ & 7.91 & 8.26 & 11.05 & 9.06 & 9.86 & 10.88 & 12.01 & 10.92 & 12.41 & 13.76 & 14.90 & 13.69 & 14.90 & 16.96 & 17.94 & 16.60 \\
\hline $\mathrm{P}_{4}-\mathrm{No}$ & 7.13 & 7.70 & 8.75 & 7.86 & 8.95 & 9.60 & 10.68 & 9.74 & 11.23 & 11.36 & 11.75 & 11.45 & 14.68 & 14.28 & 15.24 & 14.56 \\
\hline Mean & 7.48 & 7.93 & 10.60 & 8.67 & 9.17 & 10.17 & 12.74 & 10.69 & 11.74 & 12.61 & 15.25 & 13.20 & 14.46 & 15.47 & 18.70 & 16.19 \\
\hline $\begin{array}{c}\text { For } \\
\text { comparing }\end{array}$ & \multicolumn{2}{|c|}{ S. Em ( \pm$)$} & \multicolumn{2}{|c|}{ CD $5 \%$} & \multicolumn{2}{|c|}{ S. Em $( \pm)$} & \multicolumn{2}{|c|}{ CD $5 \%$} & \multicolumn{2}{|c|}{ S. Em ( $( \pm)$} & \multicolumn{2}{|c|}{ CD 5\% } & \multicolumn{2}{|c|}{ S. Em ( $( \pm)$} & \multicolumn{2}{|c|}{ CD $5 \%$} \\
\hline Fertilizer (F) & \multicolumn{2}{|c|}{0.16} & \multicolumn{2}{|c|}{0.49} & \multicolumn{2}{|c|}{0.22} & \multicolumn{2}{|c|}{0.66} & \multicolumn{2}{|c|}{0.22} & \multicolumn{2}{|c|}{0.67} & \multicolumn{2}{|c|}{0.23} & \multicolumn{2}{|c|}{0.69} \\
\hline Pruning (P) & \multicolumn{2}{|c|}{0.18} & \multicolumn{2}{|c|}{0.54} & \multicolumn{2}{|c|}{0.26} & \multicolumn{2}{|c|}{0.77} & \multicolumn{2}{|c|}{0.26} & \multicolumn{2}{|c|}{0.78} & \multicolumn{2}{|c|}{0.26} & \multicolumn{2}{|c|}{0.77} \\
\hline $\begin{array}{c}\text { Interaction } \\
(\text { FxP) }\end{array}$ & \multicolumn{2}{|c|}{1.39} & \multicolumn{2}{|c|}{6.89} & \multicolumn{2}{|c|}{2.34} & \multicolumn{2}{|c|}{6.89} & \multicolumn{2}{|c|}{2.38} & \multicolumn{2}{|c|}{6.99} & & & & 84 \\
\hline
\end{tabular}

$F_{1^{-}}$40:40:40; $F_{2^{-}}$60:60:60; $F_{3^{-}}$80:80:80 N; $P_{2} O_{5}: K_{2} O_{5}$ g/plant 
Table.3 Influence of pruning and fertilizer levels on number of fruit per plant and seed yield per plant in Jatropha curcas

\begin{tabular}{|c|c|c|c|c|c|c|c|c|}
\hline \multirow{2}{*}{$\begin{array}{l}\text { Treatment } \\
\text { Combination }\end{array}$} & \multicolumn{4}{|c|}{ Number of fruit per plant } & \multicolumn{4}{|c|}{ Seed yield (g) per plant } \\
\hline & F1 & F2 & $\mathbf{F 3}$ & Mean & F1 & F2 & F3 & Mean \\
\hline$P_{1}-100 \mathrm{~cm}$ & 170.35 & 210.32 & 240.31 & 207.10 & 371.66 & 470.09 & 554.01 & 464.97 \\
\hline$P_{2}-150 \mathrm{~cm}$ & 246.00 & 284.00 & 310.50 & 280.20 & 539.82 & 640.70 & 707.10 & 629.21 \\
\hline$P_{3}-200 \mathrm{~cm}$ & 285.15 & 378.10 & 495.80 & 386.35 & 632.41 & 855.79 & 1142.95 & 877.05 \\
\hline $\begin{array}{l}\mathbf{P}_{4^{-}} \text {No } \\
\text { pruning }\end{array}$ & 140.20 & 193.34 & 220.00 & 184.51 & 310.29 & 434.08 & 508.64 & 417.59 \\
\hline Mean & 210.42 & 266.41 & 316.65 & & 464.10 & 600.10 & 727.96 & \\
\hline $\begin{array}{c}\text { For } \\
\text { comparing }\end{array}$ & \multicolumn{2}{|c|}{ S. $\operatorname{Em}( \pm)$} & \multicolumn{2}{|c|}{ CD 5\% } & \multicolumn{2}{|c|}{ S. Em $( \pm)$} & \multicolumn{2}{|c|}{ CD 5\% } \\
\hline Fertilizer (F) & \multicolumn{2}{|c|}{21.82} & \multicolumn{2}{|c|}{63.98} & \multicolumn{2}{|c|}{49.04} & \multicolumn{2}{|c|}{143.80} \\
\hline Pruning (P) & \multicolumn{2}{|c|}{25.19} & \multicolumn{2}{|c|}{73.89} & \multicolumn{2}{|c|}{56.62} & \multicolumn{2}{|c|}{166.07} \\
\hline $\begin{array}{c}\text { Interaction } \\
\text { (FxP) }\end{array}$ & \multicolumn{2}{|c|}{43.64} & \multicolumn{2}{|c|}{128} & \multicolumn{2}{|c|}{98.08} & \multicolumn{2}{|c|}{287.66} \\
\hline
\end{tabular}

This was due to continued supply of nutrients and maintaining of photosynthetic activity of leaves throughout the growth period especially during seed filling stage which is major requirement for higher yield (Pepole et al., 1980).

Pruning levels at $150 \mathrm{~cm}$ and $200 \mathrm{~cm}$ from ground level did not show mean significant difference in collar diameter, number of branches per plant and number of fruit per plant. However, application of fertilizer in the ratio of 80:80:80 N: $\mathrm{P}_{2} \mathrm{O}_{5}: \mathrm{K}_{2} \mathrm{O}$ g/ plant gave highest number of branches, fruits and seeds per plant. The treatment combination $100 \mathrm{~cm}$ pruning level with fertilizer dose of 80:80:80 $\mathrm{N}: \mathrm{P}_{2} \mathrm{O}_{5}: \mathrm{K}_{2} \mathrm{O}$ g/ plant reported 22.10 numbers of branches while combination of 80:80:80 N:
$\mathrm{P}_{2} \mathrm{O}_{5}: \mathrm{K}_{2} \mathrm{O}$ g/ plant with $150 \mathrm{~cm}$ pruning level from ground recorded superior collar diameter growth (21.07) over all other treatment combination. Higher fruit number (495.80) and seed yield (1142.95 gram) was recorded in treatment combination of $80: 80: 80 \mathrm{~N}: \mathrm{P}_{2} \mathrm{O}_{5}$ : $\mathrm{K}_{2} \mathrm{O}$ g/ plant with $200 \mathrm{~cm}$ pruning level from ground.

\section{References}

Achten, W. M. J., Verchot, L., Franken, Y. J., Singh, V. P and Muys, B., 2008, Jatropha bio-diesel production and use (a literature review). Biomass Bioenergy, 32: 10631084.

Foidl, N., Foidl, G., Sanchez, M., Mittlebach, M. and Hackel, S., 1996, Jatropha 
curcas L. as a source for the production of biofuel in Nicaragua. Bioresour. Tech., 58: 77-82.

Gour, V. K., 2006, Production practices including post harvest management of Jatropha curcas. Proceedings of the Biodiesel Conference toward Energy Independence-Focus of Jatropha, June 9-10, Hyderabad, India, New Delhi, Rashtrapati Bhavan, pp: 223-251.

Heller, J., 1996, Physic Nut (Jatropha Curcas L.): Promoting the conservation and use of under-utilized and neglected crops. Ist Edn. International Plant Genetics and Crop Plant Research Notes, Gartersleben (IPGRI), Rome, Italy, pp: 66.

Kumar, A. and Sharma, S., 2008, An evaluation of multipurpose oilseed crop for industrial uses (Jatropha curcas L.): A review. Ind. Crops Prod., 28: 1-10.

Novoa, R. and Loomis, R. S., 1981, Nitrogen and plant production. Plant Soil., 58:
177- 204.

Raju, A. J. S. and Ezradanam, V., 2002, Pollination ecology and fruiting behavior in a monoecious species, Jatropha curcas L. (Euphorbiaceae). Curr. Sci., 83: 1395-1398.

Sujatha, M., Reddy, T. P and Mahas, M. J., 2008, Role of biotechnological interventions in the improvement of castor (Ricinus communis L.) and Jatropha curcas L. Biotech. Adv., 26: 424-443.

Tan, R. R., Culaba, A. B. and Purvis, M. R. I., 2002, Application of possibility theory in the life cycle inventory assessment of biofuels. Int. J. Energy Res., 26: 737-745.

Yin, L., Hu, T. X., Lui, A., Yao, S. F., Ma, J., Liu, W. T. and He, C., 2010, Effect of drought on photosynthetic characteristics and growth of Jatropha curcas seedlings under different nitrogen levels. Ying Yong Sheng Tai Xue Bao, 21: 569-576.

\section{How to cite this article:}

Sumed, R.G., Shahbaz Noori, G.O. Manjunath, H. Shivanna and Patil, S.K. 2019. Influence of Pruning Levels and Fertilizer Rates on Growth and Yield of Jatropha curcas L. (Physic Nut). Int.J.Curr.Microbiol.App.Sci. 8(11): 1071-1077. doi: https://doi.org/10.20546/ijcmas.2019.811.126 